\title{
A Slurry-Pot Abrasive Wear Test Device for Several Composite Materials
}

\author{
H. MUHANDES ${ }^{1}$, G. KALÁCSKA² \\ ${ }^{1}$ Szent István University, Faculty of Mechanical Engineering Technology, hasanmuhandes@gmail.com \\ ${ }^{2}$ Szent István University, Faculty of Mechanical Engineering Technology, kalacska.gabor@gek.szie.hu
}

Abstract. To choose the proper material for agricultural machinery we tested several materials with abrasive cloth on the pin-on-plate test device. After having the pre-results, we launched more complex abrasive testing (slurry-pot) simulating more realistic mode with soils to investigate the abrasive wear mechanism and resistance of the selected up-to-date polymeric structural materials. for this, we developed a modified slurry-pot test machine that ensures the comparability of the materials over a wide range of conditions. Through this device, several parameters could be controlled like speed, the soil particle's hit angle on the tested surface.

Keywords: Slurry test - Abrasive wear - Composite materials.

\section{Introduction}

Every year there are substantial losses due to friction and wear of agricultural machine parts. Just within the high-capacity harvesters, the abrasive and erosive effects of the contaminated crops, plants, and soil particles can cause unexpected breakdown and extended service time.

The replacement of some critical fast-wearing steel parts with polymers can increase the machine reliability besides better corrosion resistance and lighter construction.

Nowadays, abrasive wear of engineering and agricultural machine components caused by the abrasive particles is a major industrial problem. Therefore, a full understanding of the effects of all system variables on the abrasive wear rates is necessary to undertake appropriate steps in the design of the machinery and the choice of materials to reduce/control wear [1].

A pin-on-disk system has a wide range of use, one of its applications is to study the mechanical and abrasive wear behaviour of nylon 6 and glass fiber reinforced (GFR) nylon 6 composites specimens for several conditions like grit size abrasive paper and temperature under humid atmospheric condition [2].

Another application is to study the effect of the mass load (static) and vibration loads (dynamic) which are the result of the vibration of the machine elements for several materials on fatigue-sliding models, usually generates these loads. The authors gave an idea of how the loads can affect the friction coefficient and the wear [3].

There is a lot of designs of abrasive wear tester, one of them is depending on rotating and sliding against a fixed sample by a driven wheel or ball by a motor, in the presence of abrasive particles. By adding or removing weight on the loading lever, we can control the contact pressure. Moreover, to 
have a three-body wear situation, the abrasive particles can be inserted through a nozzle. This abrasive wear tester illustrated in figure 1 [4].

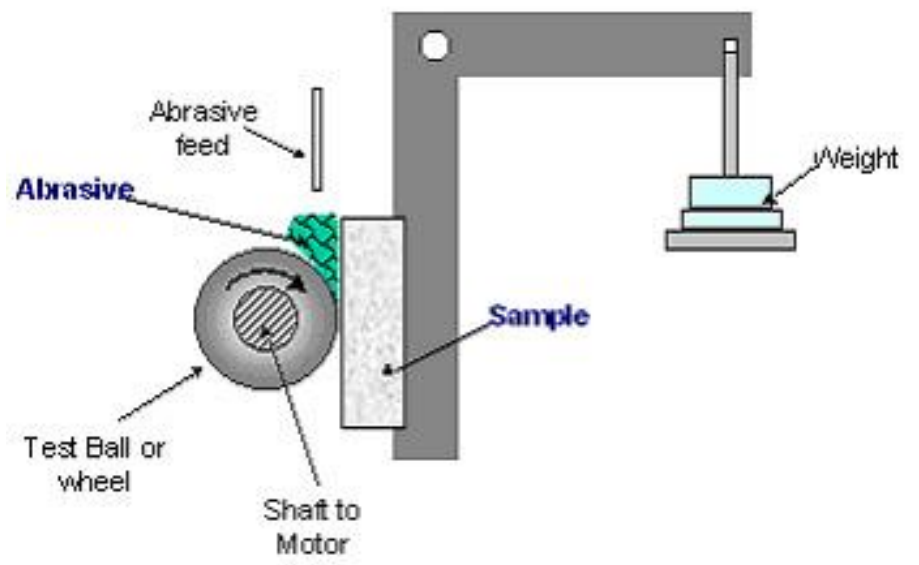

Figure 1. An abrasive wear tester.

In our last test, Pin-on-Plate system was used to know the abrasive wear behaviour for several composite materials; figure 2 shows the used pin-on-plate system.
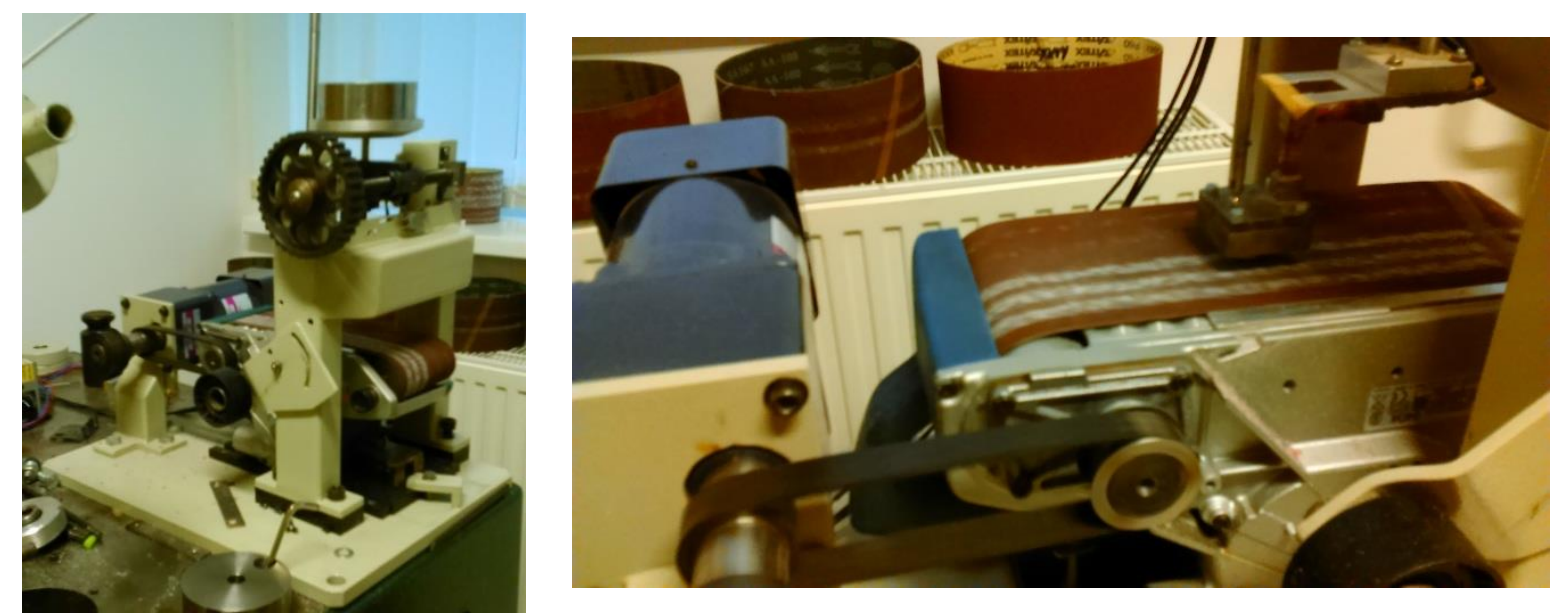

Figure 2. Pin-on-plate wear device.

We were able to control several parameters like the load, the speed and the abrasive media [5].

\section{Materials and methods}

In our last research we tested several composite materials in the standard abrasive test, we wanted to check these materials in the real mode, in other words when these materials are in contact and friction with soils.

Testing these materials on the real harvester has several obstacles:

1- In the beginning, manufacture these materials in the same shape of the fast-wearing steel parts is a hard thing, especially we are in the testing phase.

2- Because we want to measure the daily wear rate and dimensions changing, it will also be hard to install and uninstall these parts every day.

3- If we can make the previous two points, we are not able to test these materials in the same conditions, which is an essential point. 
So we want to design a new testing device for testing these materials with the abrasive media in a simple way, with a possibility to measure the changes every day and of course of examining all the composite materials in same conditions.

These three concepts were the main points of our design.

To consider these three concepts, the first point in our design was that the sizes of the specimens and the size of the holders which will hold them. This size should be acceptable for testing in a laboratory device, the dimensions of the samples were $120 \mathrm{~mm}$ as length, $20 \mathrm{~mm}$ as width and $6 \mathrm{~mm}$ as thickness, so our starting position was the specimens' holder (figure 3 ).
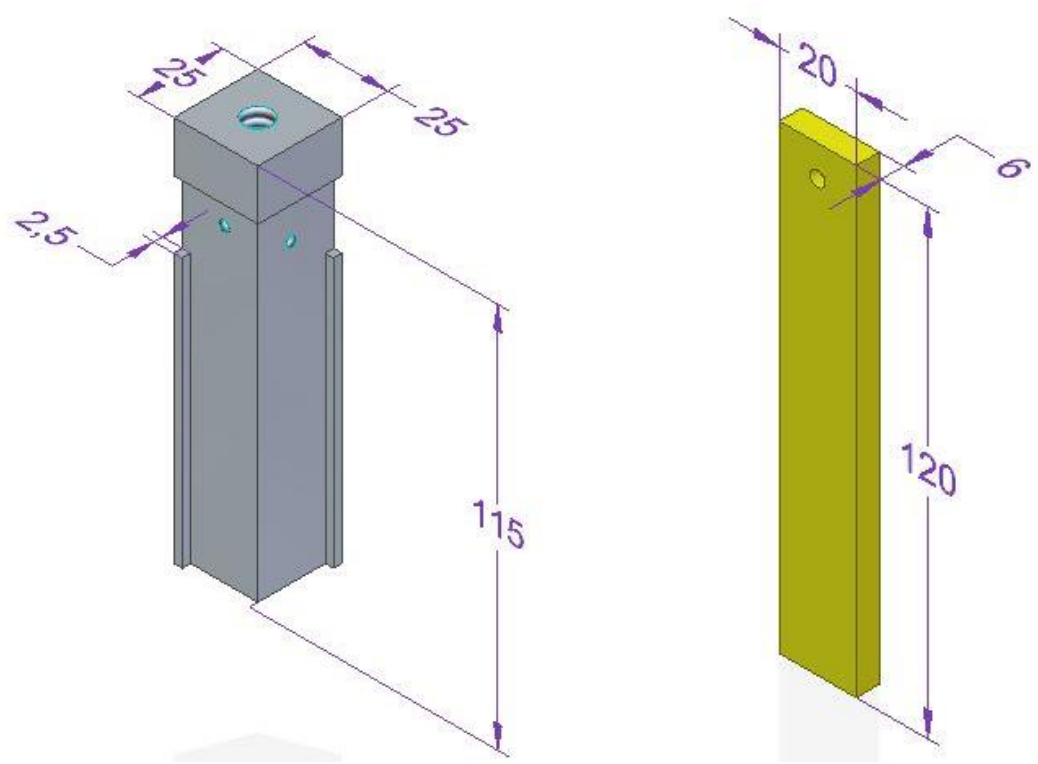

Figure 3. Specimens and Specimens' holder.

After we decided the size of the specimens, we wanted to test the materials with the same conditions.

Preparing or having the same conditions every time is such a hard or almost impossible thing, so the best choice is to test all materials at the same time, by that we will ensure the same conditions.

Because we had six materials in the previous test, we used six holders, one for each composite material (figure 4).

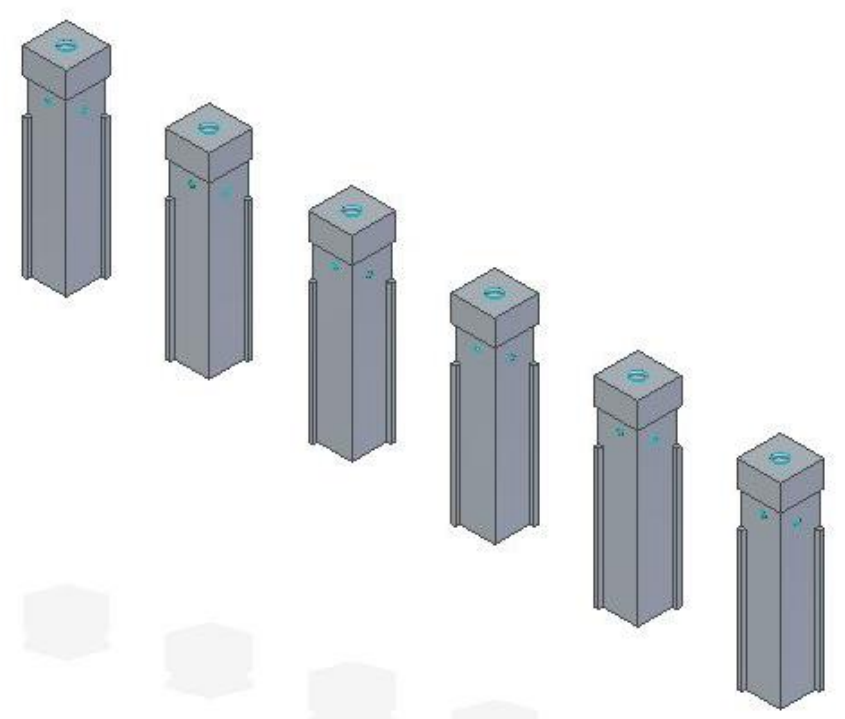

Figure 4. Six specimens' holders. 
One of the parameters that we wanted to control is the effect of the speed on the wear rate. On our previous test, we have two speeds. To control the speed, we have two ways, repeat the test with a different speed but this could lead to have different test conditions or add a new six holders to our design. And this what we did as we can see in figure 5.

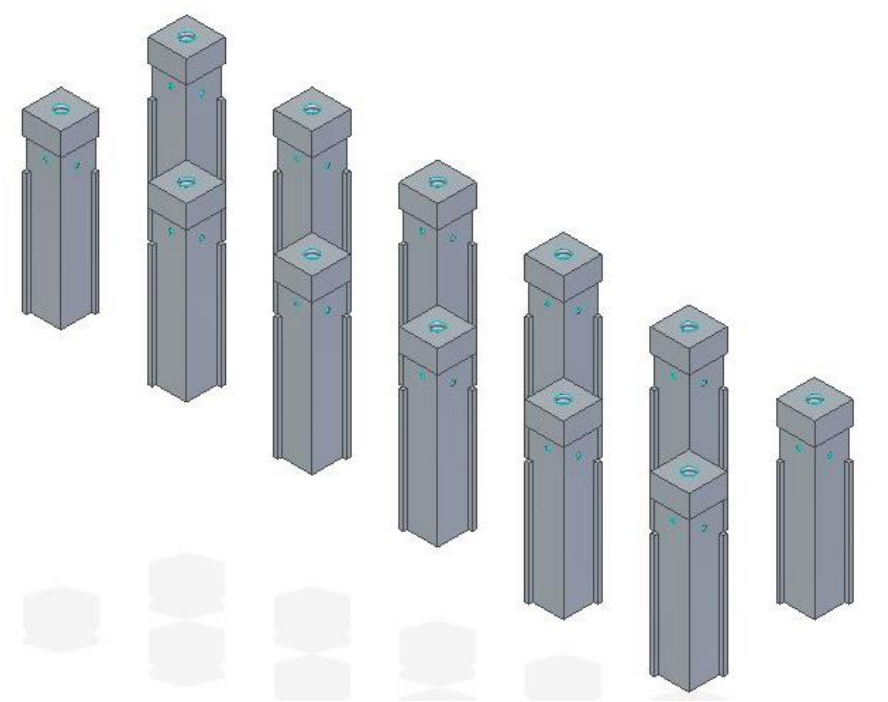

Figure 5. Twelve specimens' holders to control the effect of the speed.

As a linear motion, we are not able to have two speeds at the same time. So changing the design to a rotation motion was the solution for this case.

So we fixed these twelve holders on a disc with two positions by using two radiuses. An outer radius $r_{1}$ and an inner radius $r_{2}$.
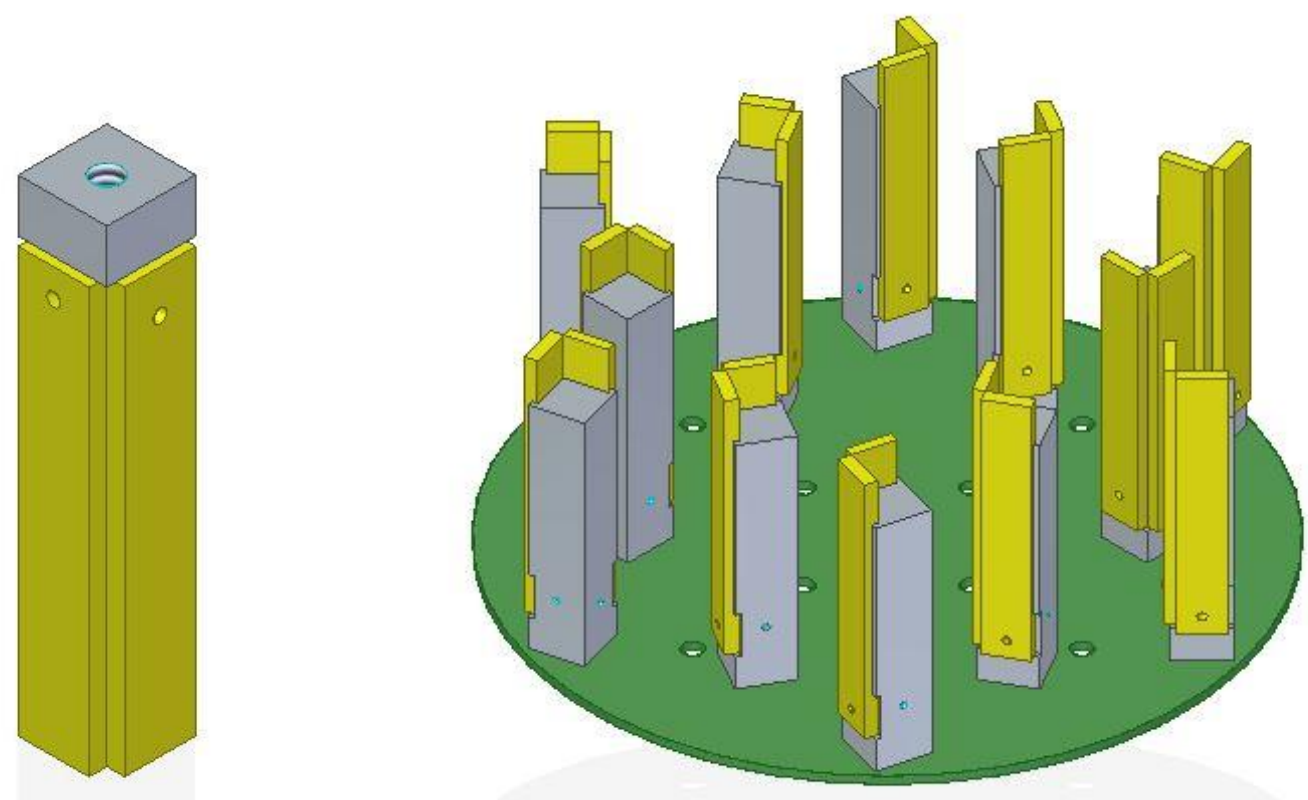

Figure 6. Twelve specimens' holders fixed on a disc to have two speeds.

Since we have:

$$
v=\omega \cdot r
$$

The angular velocity $\omega$ is constant for the disc; the two radiuses will give us two speeds, the outer diameter will provide us with a higher speed than the inner one. 


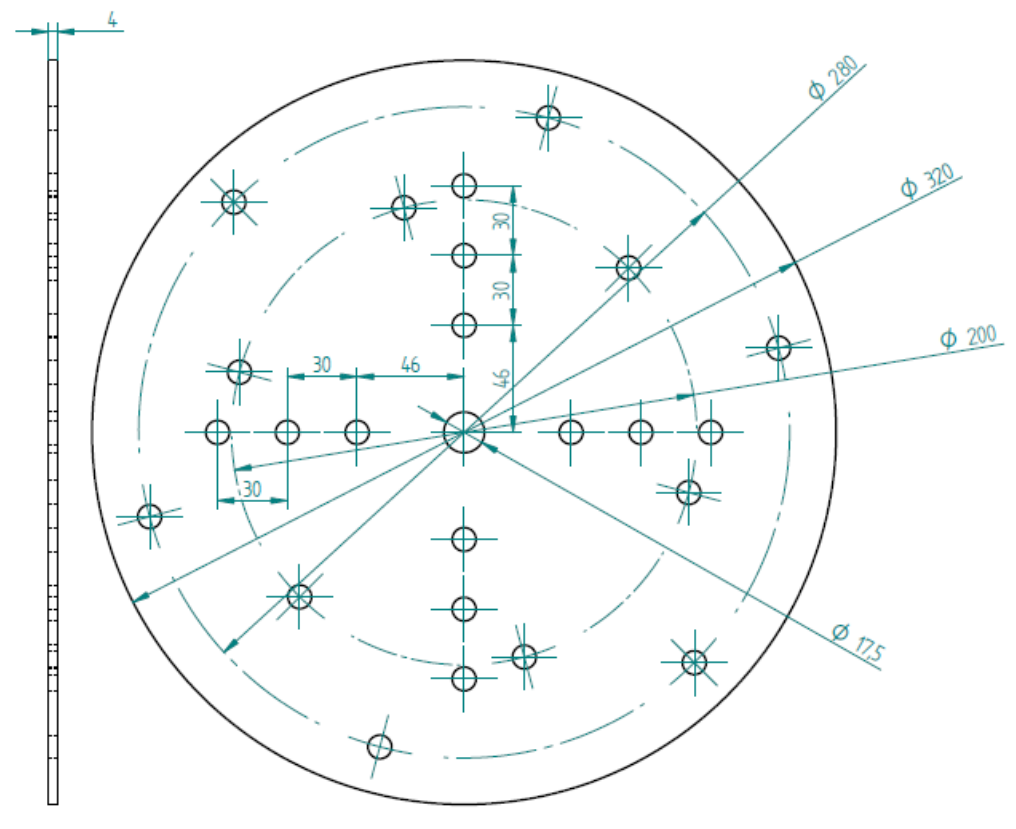

Figure 7. The design of the disc.

The twelve holders were divided into six groups as we can see in figure 8, one for each composite materials, each group has an outer and an inner holder, by that we can test and compare all materials with two speeds. The first speed is $1.456 \mathrm{~m} . \mathrm{s}^{-1}$, while the second one is $2.038 \mathrm{~m} . \mathrm{s}^{-1}$.

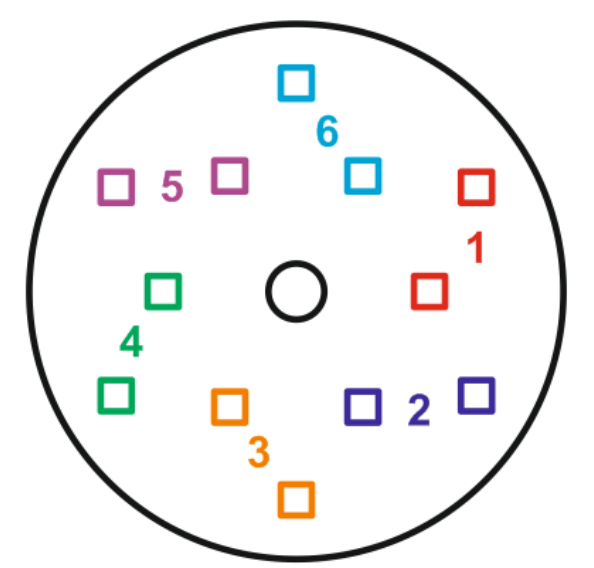

Figure 8. Dividing the holders into six groups.

By immersion these twelve holders in a pot which contains the wear media this will ensure good contact and friction conditions between the composite materials and the wear media.

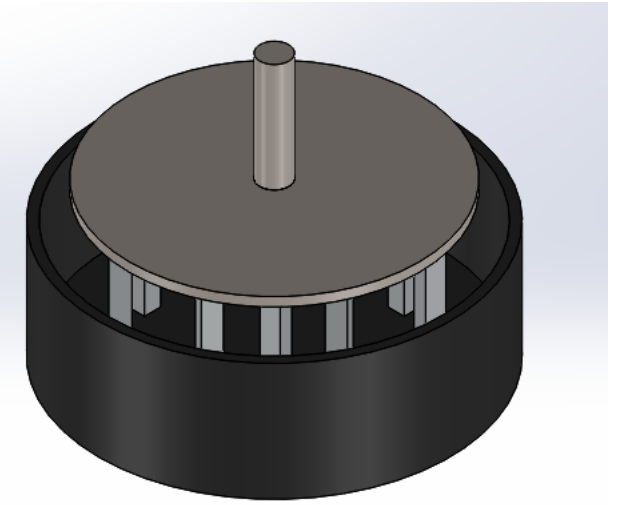

Figure 9. The twelve holders are in the pot. 
The disk will derive its movement from a motor by a gearbox through a shaft, as we can see in figure 10 .

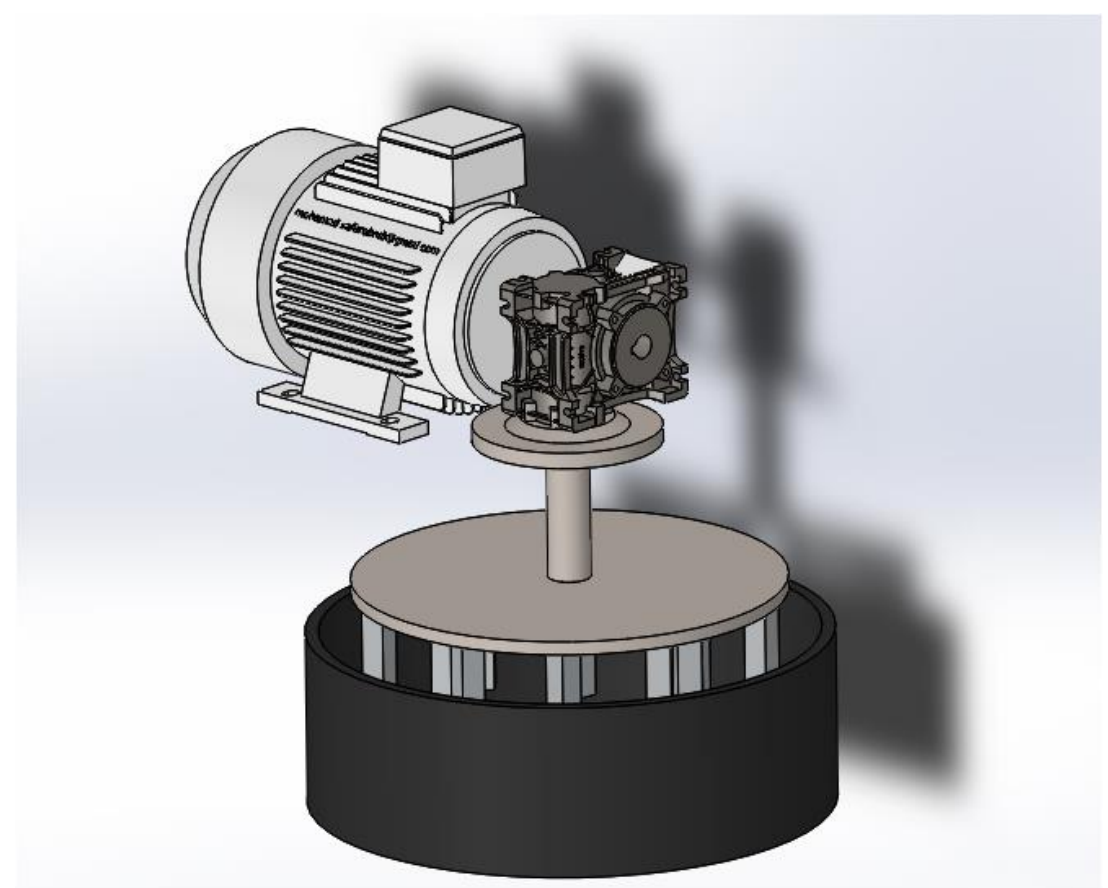

Figure 10. The full design.

Another factor that we can study is the effect of the contact angle between the specimens and the abrasive media on the wear rate. The idea of this factor came by rotating the holders about their axes; this rotation gave two cases of contact, as we can see in figure 11.

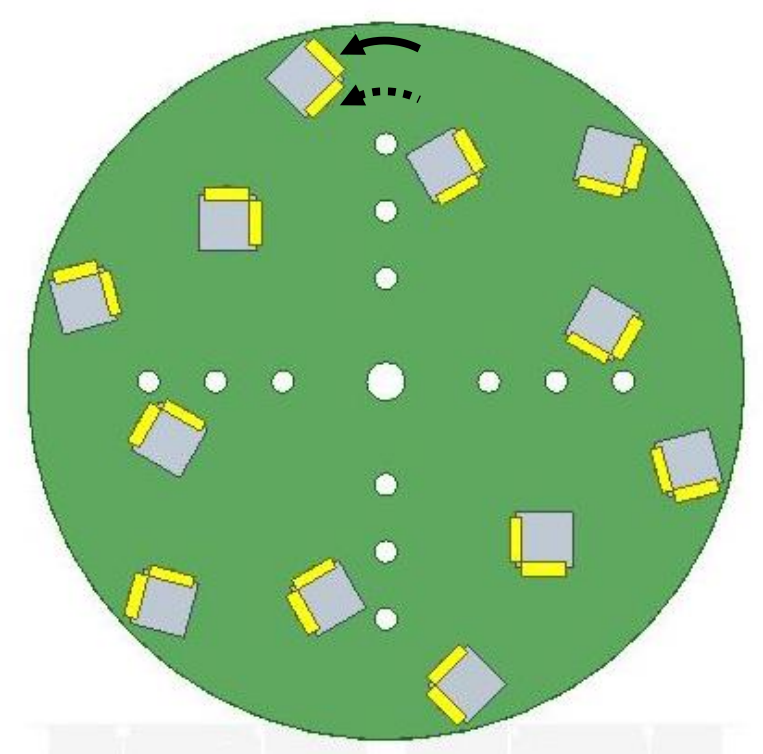

Figure 11. The two contact situations between abrasive media and specimens.

In the continues line, the abrasive media will hit the specimen almost in a straight way, and that will lead to pit the surface.

While in the dotted line, the contact will be almost tangential contact, and that will lead to scratch the surface. 
This device allows for studying several factors:

- Study the effect of speed on wear rate.

- Study the effect of friction angle on wear rate.

- Study the effect of abrasive media on wear behaviour, since we can use several abrasive media.

A trial test was run to check this system, twenty-four specimens were used representing the six kinds of composite materials, and after three working days, we can see that the specimens lost the sharp edges and wear took place in different values according to the controlled parameters.

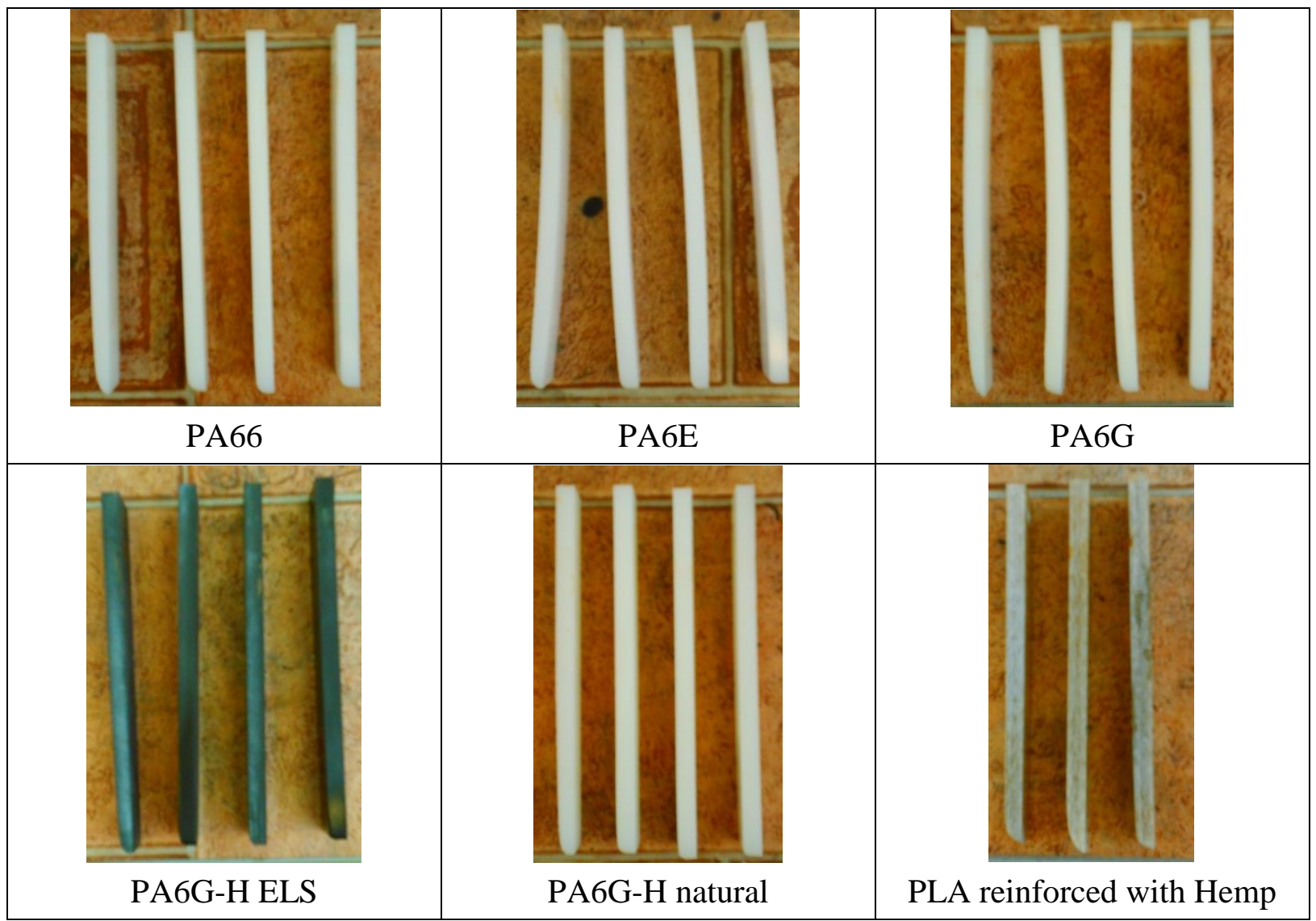

Figure 12. the specimens after three working days as a trial test.

\section{Conclusion}

To investigate the abrasive wear mechanism and resistance of the selected up-to-date polymeric structural materials, a new test system was introduced to test the suggested materials in a more realistic way where the materials are in contact with soil and crops. This system allows studying the effect of speed on wear rate, the effect of friction angle on wear rate and the effect of abrasive media on wear behaviour. 


\section{References}

[1] V. Mishra (2014) Physical, Mechanical and abrasive wear behaviour of jute fiber reinforced polymer composites. Doctoral dissertation, National Institute of Technology, India.

[2] S. Kumara - K. Panneerselvam (2016) Two-body Abrasive Wear Behavior of Nylon 6 and Glass Fiber Reinforced (GFR) Nylon 6 Composite. Procedia Technology. 25 pp. 1129 - 1136.

[3] Á. Sarankó - G. Kalácska - R. Keresztes (2017) Developed polymer pin-on-disc test system for fatigue-sliding models. International Multidisciplinary Conference, 12th Edition.

[4] Li, C. X. (n.d.) Surface Engineering. Retrieved June 24, 2017, from Wear Testing and Wear Measurement: $\quad$ http://emrtk.uni-miskolc.hu/projektek/adveng/home/kurzus/ korsz_anyagtech/1_konzultacio_elemei/wear_testing_measurement.htm

[5] H. Muhandes - G. Kalácska - N. Kadi - M. Skrifvars (2018) Pin-on-Plate Abrasive Wear Test For Several Composite Materials, Proceedings. 2 (8) 469. doi:10.3390/ICEM18-05333. 